\title{
Lagunas Jurídicas y Neoconstitucionalismo: la plenitud del ordenamiento jurídico en el Estado Constitucional de Derecho
}

\section{Loopholes and Neo-constitutionalism: fullness of the Legal System in a Contitutional State of Law}

\author{
J. Ignacio Núñez Leiva \\ Magister en Derecho Público de la \\ Universidad Católica de Chile \\ Profesor de la Universidad Andrés Bello (Chile) \\ jinunez@uc.cl
}

Recibido: 13/03/2012 Aceptado: 11/07/2012

\section{RESUMEN}

El presente trabajo analiza el impacto de la Constitucionalización del Derecho, especialmente del denominado Neoconstitucionalismo, en el fenómeno de las lagunas normativas. Destaca que en el contexto descrito las Cartas Fundamentales disiparían las lagunas normativas

\section{PALABRAS CLAVE}

Constitucionalismo, Neoconstitucionalismo, Lagunas Jurídicas

\section{ABSTRACT}

This essay analyses the (Neo)constitutionalization of law's impact in the phenomena of loopholes. In this sense, this paper explains that a Constitution can dissolve a normative loopholes.

\section{KEYWORDS}

Constitutionalism, neoconstitutionalism, loopholes.

\section{PROLEGÓMENOS}

La figura de las Lagunas Jurídicas - entendidas como falta de integridad en el ordenamiento jurídico, especialmente en la ley - no es algo nuevo. Su formulación ha recibido diversos tratamientos durante la historia del pensamiento jurídico. Con todo, se estima que bajo el paradigma del Estado Constitucional de Derecho su análisis debe considerar ciertas coordenadas específicas. Aquellas serán reseñadas, empleando el siguiente orden: primero se hace referencia muy someramente al "problema" de las Lagunas en el Derecho. Luego, explicitaremos el contexto donde actualmente tal problema acontece para finalizar proponiendo que las Lagunas del Derecho se disipan (al menos en una magnitud importante) ante la presencia de normas de principio en las Cartas Fundamentales. 


\section{EL PROBLEMA LAS LAGUNAS EN EL DERECHO.}

La relación antagónica entre plenitud del Derecho y lagunas jurídicas admite distintas formulaciones. Ellas dependen de respecto de quien se predique (o pretenda) la plenitud o integridad: del Derecho o de ciertas fuentes preexistentes. Si la plenitud se declara respecto de ciertas fuentes formales establecidas con anterioridad al juzgamiento de los asuntos, como la ley u otra reconocida, y estamos ante un caso no resuelto por ellas, entonces hay lagunas jurídicas. En cambio, si la plenitud se expresa respecto del Derecho, entendiéndolo como un sistema integrado por diversas fuentes, no necesariamente formuladas (como la costumbre) ni siempre promulgadas oficialmente con anterioridad a los hechos juzgados (como las decisiones judiciales) el problema de las lagunas se diluye, pues todo caso podría ser resuelto con base en este sistema de fuentes múltiples. Así lo afirma, entre otros, el maestro Prieto Sanchís, quien expresa que si admitimos que del Derecho forman parte también las decisiones judiciales y que éstas deben decidir todo caso con arreglo a las fuentes o de cualquier otra manera, entonces el problema desaparece: siempre tendremos respuesta (Prieto, 2008, p.124)

El problema de las Lagunas en el Derecho (evidentemente) no es nuevo. Según Chaissoni, ya habrían referencias a ellas por parte de Justiniano en la Constitución Tanta que dispone la promulgación del Digesto. Pareciera ser que a finales del siglo XIX y comienzos del XX su existencia fue problematizada desde una perspectiva diferente. Antes de aquella época, el asunto fue percibido únicamente como un problema de práctica forense. En cambio, a finales del siglo XIX la existencia de las lagunas jurídicas fue el estandarte de lucha de ciertos autores para combatir a tres enemigos. Primero el modelo de organización estatal centralizada, heredera del Estado absolutista, en especial su monopolio tanto de la producción normativa como de la fuerza. Segundo, a la doctrina jurídica que le servía de fundamento: el positivismo de la época, curiosamente continuador de la tradición metodológica subsuntiva del derecho natural. Y tercero, la tesis de la auto integrabilidad hermenéutica del Derecho, según la cual cualquier eventual espacio de falta de integridad del ordenamiento jurídico (especialmente de la Ley) podía ser completado mediante la regeneración del mismo (Chaissoni, 2004, p.167)

La existencia de las lagunas, su definición y clases, la manera de colmarlas, los insumos para ello y su relación con la interpretación-aplicación de las normas, son asuntos que comprometen esferas tan diversas como la Teoría y Filosofía del Derecho, especialmente a través del concepto mismo de Derecho y la teoría de sus fuentes, la Teoría y Filosofía Política, por intermedio de la noción de separación de poderes, y - en general - al Derecho Público, a causa del rol que hoy en día corresponde jugar a las Constituciones en la fundamentación de los sistemas normativos.

Sin perjuicio de que el positivismo (escolástico llamado por Kantorowicz) de la Escuela de la Exégesis y de la Jurisprudencia de Conceptos, estimulado por el movimiento codificador, a comienzos de 1900 negó tajantemente la existencia de lagunas en el Derecho, ilustres representantes del positivismo ya más avanzado el siglo XX arribaron a la misma conclusión pero fundados en razones diversas. Tal es el caso de Kelsen y su tesis de la plenitud del Derecho, basada en la idea de que todo lo no prohibido se encuentra permitido (Bulygin, 2009, p.14) Otros positivistas, en cambio, no sólo aceptaron la existencia de lagunas en el Derecho, sino que también distinguieron con precisión sus diversas clases. Nos referimos a Carlos Achourrón y Eugenio Bulygin (Achourrón, C. \& Bulygin, E, 1974)

\section{CONTEXTO}

El denominado Neoconstitucionalismo - como afirma Luis Prieto - es una expresión cada vez más difundida, que sirve para aludir, de forma no siempre muy precisa, a distintos aspectos de una presunta nueva cultura jurídica (Prieto, 2009, p. 101). En efecto, cuenta con muy pocos militantes 
declarados y numerosos autores son sindicados como parte de este "movimiento" sin que el rótulo les satisfaga del todo. Muchos hablan de él sin tener absoluta claridad de sus características - cuestión bastante compleja de lograr, si se trata de un concepto polisémico - y otros tantos se instalan como sus acérrimos críticos sin notar que sus objeciones no son verdaderamente en contra del Neoconstitucionalismo. La razón de todo esto es explicada con precisión por el mismo Prieto en su trabajo Neoconstitucionalismos, un catálogo de problemas y argumentos, recientemente publicado en el $N^{0} 44$ de la Revista Anales de la Cátedra Francisco Suárez:

Se puede enarbolar el Neoconstitucionalismo en sentidos muy distintos y, luego, una vez fijado el sentido, tampoco resultan nada claros los rasgos o elementos que han de concurrir para ostentar legítimamente dicho título.

Por eso estima justificado hablar de Neoconstitucionalismos. Propone además que los distintos Neoconstitucionalismos se desarrollan en torno a problemas también diferentes e identifica cuatro modalidades o acepciones, pero advirtiendo que ni están implicadas entre sí, de manera que en principio es posible adherirse a cualquiera de ellas sin necesidad de asumir las demás; ni por otro lado su presentación cuenta tampoco con un esquema canónico o incontrovertido de tesis fundamentales (Prieto, 2011). Con todo, como doctrina totalizante, tiende a ser confrontada a las construcciones de la misma índole que han dominado el pensamiento jurídico durante el último tiempo: el iuspositivismo y el iusnaturalismo (ante todo el teológico).

Tales cuatro variables son: en primer lugar el Neoconstitucionalismo como un tipo de Estado de Derecho (una doctrina del Estado Justo), en segundo, como Teoría del Derecho - que propone la superación de la teoría positivista - en tercero como Filosofía y Concepto del Derecho, que aborda la cuestión de la existencia o no de una conexión conceptual entre Derecho y Moral, y en cuarto lugar como tipo de Ciencia Jurídica (Prieto, 2009, p.102) comprometida ( García F, 1998, p.205) (Sastre, 1999, p.205)

Este movimiento o conjunto de doctrinas - que no puede ser calificada de Escuela, dadas sus profundas divergencias y apreciable falta de coherencia interna - con todo, tiene un origen común que en rigor es posterior a las transformaciones institucionales relevantes que reporta. Sus desarrollos descriptivos y doctrinarios acontecieron en sede académica y no necesariamente política. Su génesis procede de la forma de organización política que viene abriéndose paso en Europa - y que desde allí ha influido a Sudamérica - desde mediados del siglo pasado. Se trata de un modelo de organización política que, como tal, no reúne en todas sus manifestaciones signos de uniformidad, pero sí algunos rasgos generales compartidos que permiten hablar de algo diferente, no radicalmente nuevo (a esta altura de la historia de la humanidad nada prácticamente lo es) pero si distinto a los que pudo representar el Estado de Derecho Decimonónico.

En este sentido el Neoconstitucionalismo es el resultado de la convergencia de dos tradiciones constitucionales que desde sus comienzos caminaron separadas (Prieto, 2007, p. 111) geográfica y filosóficamente: una primera que concibe a la Constitución como regla de juego de la competencia social y política, como pacto de mínimos jurisdiccionalmente garantizado que permite asegurar la autonomía de los individuos como sujetos privados y como agentes políticos a fin de que sean ellos en un marco democrático y relativamente igualitario, quienes desarrollen su plan de vida personal y adopten en lo fundamental las decisiones colectivas pertinentes en cada momentos histórico. En líneas generales esta es la tradición originaria de los Estados Unidos de Norteamérica, que se cimenta en la idea de supremacía constitucional y en su consecuente garantía jurisdiccional (Prieto, 2009, p.107).

La segunda tradición, en cambio, entiende a la Constitución como la encarnación de un proyecto político estrictamente articulado con intenciones 
transformadoras y transicionales (Prieto, 2009, p.112). En esta segunda tradición la Constitución no es sólo una regla del juego sino parte del mismo a través de la inclusión de numerosas disposiciones materiales 0 de principio, en suma cláusulas materiales o con denso contenido axiológico que pretenden incidir en la agenda política en áreas tan diversas como el modelo económico o la acción del Estado en las esferas de educación o sanida ( Prieto, 2009, p.108).

También en líneas generales este es el modelo iniciado por la Revolución Francesa, que pese a basar su sistema en una norma suprema, confirió la competencia de ponerlo en marcha a la acción política del parlamento, depositario de la soberanía popular en términos rousseaunianos, es decir, ilimitados, y por tanto, carente de controles heterónomos. Ambas reseñas de las mencionadas tradiciones son, sin lugar a dudas, síntesis que simplifican al máximo los hechos. Sería erróneo pensar que la Constitución de los Estados Unidos careciese absolutamente de normas sustantivas y estuviere exclusivamente poblada por normas procedimentales y de competencia (Prieto, 2009, p.109). En igual equivocación se incurriría si se sostuviese que el modelo francés careció de toda clase de control de la vigencia de la Carta Fundamental. Con todo, las matrices generales de ambas son claras y dispares.

El Neoconstitucionalismo, como conjunto de doctrinas, reúne y destaca los elementos diferenciadores de ambas tradiciones: (1) un fuerte programa normativo cargado axiológicamente en especial dirigido al legislador como ocurrió en Francia, pero sin controles heterónomos, y (2) la garantía jurisdiccional para que aquello se cumpla, y no sólo por aquél sino por cualquiera, tal como lo idearan los estadounidenses a través de la Judicial Review.

De las constituciones garantizadas al estilo revolucionario estadounidense - afirma Prieto deriva una noción de poder Constituyente más liberal que democrático, que se traduce en la existencia de límites frente a las decisiones de la mayoría, no en el empoderamiento de la ciudadanía a través del legislador. De las constituciones que siguen el modelo francés se sigue un ambicioso programa político (Prieto, 2007, p.114) que va mucho más allá de la mera organización del poder mediante las reglas del juego político, designa como artífice de las transformaciones perseguidas al legislador: un constitucionalismo más democrático que liberal.

En pocas palabras, el resultado de esta combinación, es decir el sustrato del Neoconstitucionalismo, podría resumirse asi: la existencia de sistemas normativos encabezados por una Constitución imbuida por un esquema particular de separación de poderes - que pretende condicionar de modo importante las decisiones de las mayorías a través de su carga axiológica y de las instituciones jurisdiccionales que garantizan su supremacía y en donde, a consecuencia de lo anterior, el protagonismo en la concreción de las disposiciones constitucionales no corresponde al legislador sino a losjueces.

\section{LAS LAGUNAS DEL DERECHO SE DISIPAN EN MEDIO DE LAS CRIATURAS DE LA MORALIDAD}

En el contexto del Estado Constitucional de Derecho las criaturas constitucionales - principios y directrices - son Bellas Criaturas de la Moralidad, afirma Alfonso García Figueroa (siguiendo a Dworkin), pero a la vez terribles criaturas de poder (García F, 2009, p.21)

La condición - el espíritu del tiempo en que vivimos expresa Zagrebelsky, deambula no entre uno sino entre varios principios o valores que configuran la convivencia colectiva: la libertad versus las reformas sociales, la igualdad genérica versus las legítimas diferencias en los casos concretos, la protección de los derechos individuales, pero también la de los sociales (Zagrebelsky, 2008, p.26). Si cada valor se entendiese como absoluto, sería imposible admitir la coexistencia de unos junto a otros. Si cada valor fuere a priori determinado o determinable, no existiría aquella tendencial incompatibilidad entre ellos 
mismos y entre los diversos proyectos que albergan.

Las Constituciones actuales están dotadas no sólo de normas formales, de competencia o procedimiento, dirigidas a orientar el ejercicio de los poderes estatales y la relación entre los mismos, sino también - y sobre todo - de normas sustantivas que pretenden trazar límites negativos y vínculos positivos a lo que dichos poderes están en condiciones de decidir legítimamente. Siguiendo al mismo autor, justamente aquello que Kelsen temía es el sello de identidad de este nuevo Derecho: gira en torno y se subordina a derechos, valores, principios y directrices (Prieto, 2007, p.215).

En efecto, estas nuevas piezas fundamentales del Derecho son normas "muy generales", "redactadas en términos particularmente vagos", son "programáticas" en el sentido de que imponen la obligación de perseguir determinados fines, "expresan los valores superiores del ordenamiento jurídico" y sirven como "criterio de interpretación del Derecho subconstitucional", por mencionar solamente algunos de los sentidos o características con que según Atienza y Ruiz Manero se les ha atribuido (atienza \& Ruiz, 1996, p.4).

Tal vez, los elementos más importantes en las Cartas Fundamentales actuales sean los principios y las directrices. Los primeros se caracterizan por estar formulados como enunciados que correlacionan siempre casos con la calificación normativa de una determinada conducta, pero de manera abierta. A diferencia de las reglas, carecen de una condición de aplicación determinada. No se trata de que posean una condición de aplicación con una periferia más o menos amplia, sino de que tales condiciones no se encuentran ni siquiera genéricamente determinadas. Las segundas se distinguen porque no sólo sus condiciones de aplicación son abiertas o aplicables a - prácticamente - infinitos supuestos de hecho sino porque además su consecuencia jurídica (su modelo de conducta prescrita) tampoco está determinada (Atienza \& Ruiz, 1996, p.9-10).

La particularidad (funcional) de los principios estaría dada - en el paradigma actual - en que mientras las reglas, normas binarias, altamente determinadas en sus condiciones de aplicación y consecuencias jurídicas, proporcionan pautas nítidas acerca de cómo debemos, no debemos o podemos actuar, los principios no nos dicen nada a este respecto, pero si nos entregan criterios para adoptar posiciones ante situaciones concretas, pero que en principio, no aparecen de manera evidente contenidas en su espectro normativo (Zagrebelsky, 2008, p.110). Los principios, no tienen eficacia en abstracto, requieren de casos concretos para ser operativos.

Hoy en día los principios (y directrices) colman el Derecho subconstitucional, imponiéndose a las normas fundadas en la Carta Fundamental cuando ellas contravienen su contenido o conducen a situaciones injustas. Tal efecto propio de la supremacía constitucional deviene en esencial al interior de la relación principio constitucional-norma legal. Sin embargo, como advierte Alfonso García Figueroa, la novedad del paradigma actual no consiste en la capacidad anulatoria negativa de la Constitución (perfectamente compatible con el positivismo Kelseniano e inclusive con el Ferrajoliano), sino en la irremontable tensión interna de ella. En efecto, en un Estado Constitucional, la visión holista del Derecho, especialmente estimulada por el denominado efecto irradiación, se acentúa por la existencia de normas de principio.

El carácter de los principios, derrotables pero a la vez capaces de triunfar indefinidamente sobre otra norma, sea 0 no que goce de supremacía constitucional, anuncia una endémica característica de las Cartas Fundamentales en el Estado de Derecho fundado en ellas: la omnipresencia constitucional. Esto, no sólo implica que hoy en día es difícil detectar un caso que resulte irrelevante desde el punto de vista constitucional, sino que cualquier principio (constitucional) no absoluto puede ser desplazado por otro principio concurrente. Tal aparente debilidad intraconstitucional, lejos de revelar un defecto, da cuenta del inmenso potencial de las Constituciones en los estados pluralistas: contribuyen a lograr - o más bien restablecer - un 
ideal pre codificador que la ilustración transformó de aspiración en realidad artificial, la Plenitud del Derecho (García F, 2009, p.139).

En efecto, como sostiene Juan Carlos Bayón, la existencia de conductas no reguladas será tanto más improbable cuanto mayor sea la presencia en el ordenamiento de normas que definan con muy altos niveles de abstracción los casos genéricos que regulan, pues a mayor nivel de abstracción, mayor será el número de casos individuales a los que resultarán aplicables ( Bayón, 2009, p.38). Y como sabemos, la presencia de disposiciones abstractas con alta densidad axiológica - al menos a nivel de Cartas Fundamentales - es uno de los hechos que reporta (e incluso fomenta) el constitucionalismo contemporáneo. Eso es lo que Alfonso García quiere expresar cuando afirma que: en el panorama de la Filosofía del Derecho Contemporánea se observa que el recurso a los principios sirve para justificar la eliminación de las lagunas en el Derecho (García F, 1998, p.58).

La presencia de dicha clase de normas en los ordenamientos constitucionalizados, sumado a su aplicación directa, producen como consecuencia que la existencia de eventuales lagunas se vea significativamente disminuida, puesto que cualquier caso aparentemente no regulado, puede terminar siendo correlacionado con alguna disposición Constitucional. Debido a que la Constitución ya dejó de contener únicamente normas de competencia y procedimiento puede servir para colmar las lagunas de la ley.

Así, hoy, mientras muchos - principalmente positivistas - reconocen la existencia de lagunas y afirman que cuando el juez decide un caso no regulado ejerce mera discrecionalidad, las tesis contemporáneas de la aplicación directa y de la sobreinterpretación de la Constitución, propondrán que el juez frente a un caso sin regulación legal no debe ejercer mera discrecionalidad, sino que aplicar el Derecho contenido en la Constitución.

Si todos los principios jurídicos carecen de condiciones de aplicación, su eficacia concreta es ilimitada y -por lo tanto - las pautas morales contenidas en las constituciones son capaces de disipar cualquier laguna, pues allí donde no llega una regla legal siempre puede hacerlo un principio constitucional, abierto en condición de aplicación o en su consecuencia normativa (Prieto, 2010, p.97). Tal como sostenía el Movimiento del Derecho Libre hace casi más de un siglo, la ley contiene lagunas "hay tantas lagunas como palabras" - pero esta vez hay Derecho (constitucional) para colmarlas.

\section{CONCLUSIONES}

De lo expuesto a lo largo del presente trabajo se puede sintetizar y reflexionar lo siguiente: El problema de la eventual existencia de lagunas jurídicas se ve potenciado en el contexto del denominado Estado Constitucional de Derecho, en especial, bajo las ideas que difunde el paradigma Neoconstitucionalista debido a que el mencionado panorama teórico incorpora factores no necesariamente contemplados por la teoría jurídica incubada al alero del Estado Legislativo de Derecho.

El Neoconstitucionalismo, como conjunto de doctrinas, reúne y destaca los elementos distintivos de diferentes tradiciones: un fuerte programa normativo cargado axiológicamente especialmente dirigido al legislador (como ocurrió en Francia, pero sin controles heterónomos) y la garantía jurisdiccional para que aquello se cumpla, y no sólo por aquél sino por cualquiera, tal como lo idearan los estadounidenses a través de la Judicial Review.

Hoy, en tiempos del denominado Estado Constitucional de Derecho, parecen haber sido alteradas las posiciones que respecto de las lagunas mantenían las teorías omnicomprensivas del Derecho. Mientras en el pasado la existencia de estas fue negada por las versiones más radicales del positivismo (verdaderamente el paleopositivismo) hoy lo es por el no-positivismo neoconstitucionalista.

En efecto, como afirma Bayón, la existencia de conductas no reguladas disminuirá en cuanto 
aumente presencia de normas constitucionales con condición de aplicación subdeterminada ya que mientras mayor sea el nivel de abstracción de la norma, más amplio será el número de casos individuales a los que resultarán aplicables. Y como se sabe, la presencia de disposiciones abstractas con alta densidad axiológica - al menos a nivel de Cartas Fundamentales - es uno de los hechos que reporta (e incluso fomenta) el constitucionalismo contemporáneo y/o los Neoconstitucionalismos. Por ello se destaca la afirmación de García Figueroa en orden a que en el panorama de la Filosofía del Derecho Contemporánea se observa que el recurso a los principios se suele emplear para justificar la eliminación de las lagunas en el Derecho.

\section{REFERENCIAS BIBLIOGRAFÍCAS}

- Alchourrón, C. \& Bulygin, E. (1975) Introducción a la metodología de las Ciencias Jurídicas y Sociales, Buenos Aires: Astrea.

- Atienza, M. \& Ruiz, J. (1996). Las piezas del Derecho, Barcelona: Ariel.

- Atienza, M. \& Ruiz, J (2009). Para una teoría postpositivista del Derecho. Lima: Palestra.

- Bayón, J. (2009). Sobre el principio de prohibición y las condiciones de verdad de las proposiciones normativas, en Bulygin, E. Atienza, M, Bayón, J. Problemas Lógicos en la teoría y práctica del Derecho. Madrid: Fundación Coloquio Europeo.

- Bulygin, E. (2009). La importancia de la distinción entre normas y proposiciones normativas. Bulygin, E. Atienza, M. Bayón, J. Problemas Lógicos en la teoría y práctica del Derecho. Madrid: Fundación Coloquio Europeo.

- Chaissoni, P. (2004). Las lagunas en el Derecho. Proyecto de voz para un vademécum jurídico. En Comanducci, P. Análisis y Derecho. México:
Fontamara.

- Ferrajoli, L. (1998). Derecho y razón. Teoría del garantísmo penal. Madrid, Trotta.

- García Amado, J. (2010). El Derecho y sus circunstancias. Bogotá Colombia.

- García Figueroa, A. (1998). Principios y positivismo jurídico: el no positivismo principialista en las teorías de Ronald Dworkin y RobertAlexy, Madrid, CEPC.

- García Figueroa, A. (2009). Criaturas de la moralidad, una aproximación neoconstitucionalista al Derecho a través de los derechos, Madrid, Trotta.

- Prieto Sanchís, L. (1993) Ideología e interpretación jurídica, Madrid, Tecnos.

- Prieto Sanchís, L. (1997): Constitucionalismo y Positivismo, México, Fontamara.

- Prieto Sanchís, L. (2005). Neoconstitucionalismo y Ponderación Judicial, en Carbonell, M. Neoconstitucionalismos, Madrid, Trotta.

- Prieto Sanchís, L. (2007): Derechos Fundamentales, Neoconstitucionalismo y ponderación judicial, Lima, Palestra.

- Prieto Sanchís, L. (2007). El Constitucionalismo de los Derechos. Carbonell, M. (Ed), Teoría del Neoconstitucionalismo. México: Trotta-UNAM.

- Prieto Sanchís, L. (2008). Apuntes de Teoría del Derecho, Trotta, Madrid.

- Prieto Sanchís, L. (2009). Justicia Constitucional y Derechos Fundamentales. Madrid: Trotta.

- Prieto Sanchís, L. (2010). Sobre la identificación del Derecho a través de la moral, en VVAA, Los Desacuerdos en el Derecho. Madrid. Fundación Coloquio Europeo.

- Prieto Sanchís, L. (2011). Neoconstitucionalismo: un catálogo de problemas y argumentos, en Anales de la Cátedra Francisco Suárez $\mathrm{N}^{0} 44$.

- Zagrebelsky, G. (2008). El Derecho dúctil, Madrid: Trotta. 